pneumonia (NSIP), 1 organising pneumonia (OP) and 1 lymphocytic interstitial pneumonia (LIP). Other pulmonary manifestations observed in our patients were: nodular lung disease ( 2 patients) and small airways disease (bronchiectasis 2 , obliterative bronchiolitis 1 ). Chest $\mathrm{x}$-ray was normal in almost half of the patients $(42.9 \%)$. Gold standard image diagnostic technique was high resolution $\mathrm{CT}$.

In respiratory function tests (PFTs) at diagnosis, only 4 patients (19\%) had a FVC $<80 \%$ and $4(19 \%)$ a DLCO $<60 \%$. In the following 2 years, in 2 patients the FVC worsened $>10 \%$ and in 5 there was a worsening of the DLCO >15\%. In 3 (14.3\%) patients PFTs were never performed and in 7 (43.7\%) were not repeated after the diagnosis.

We haven't found association between different types of pulmonary involvement and the variables analysed.

Conclusion: In our series, prevalence of RA associated lung disease is similar to that described in the literature. Lung involvement is asymptomatic and chest $\mathrm{X}$-ray is normal in most RA patients. High resolution CT is the gold standard for diagnosis.

ILD was the most frequent pulmonary involvement. Although in most patients the diagnosis of lung disease did not imply a BT change, it had an influence on the type of BT chosen for those who started treatment. Maintenance of csDMARD was not associated with a worsening of lung disease.

Screening and treatment protocols for lung disease in patients with RA in clinical practice are needed.

Disclosure of Interests: None declared

DOI: 10.1136/annrheumdis-2021-eular.3178

\section{AB0171 ACHILLES ENTHESITIS AND PLANTAR FASCIITIS IN RHEUMATOID ARTHRITIS PATIENTS: IMPACT OF BODY MASS INDEX}

K. Maatallah ${ }^{1}$, H. Boussaa ${ }^{1}$, H. Riahi ${ }^{2}$, H. Ferjani ${ }^{1}$, M. Habechi ${ }^{1}$, W. Triki ${ }^{1}$, D. Ben Nessib ${ }^{1}$, M. Bouaziz ${ }^{2}$, D. Kaffel ${ }^{1}$, W. Hamdi ${ }^{1}{ }^{1}$ Mohamed Kassab Institute of Orthopedics, Rheumatology, La Manouba, Tunisia; ${ }^{2}$ Mohamed Kassab Institute of Orthopedics, Radiology, La Manouba, Tunisia

Background: Enthesitis is known as a hallmark of spondyloarthitis. However, the growing use of ultrasonography (US) increased our opportunity to encounter enthesitis in rheumatoid arthritis (RA). The involvement of Achilles tendon and the plantar fascia is not rare in RA patients.

Objectives: The aims of this study were to determine the prevalence of Achilles enthesitis and plantar fasciitis in RA patients, and to identify association with clinical data.

Methods: We conducted a cross-sectional study including patients with RA (ACR/EULAR 2010). Demographic and clinical data were collected. Three groups were defined according to the BMl: normal $\left(B M l<25 \mathrm{~kg} / \mathrm{m}^{2}\right)$, overweight $\left(\mathrm{BMl} \geq 25 \mathrm{~kg} / \mathrm{m}^{2}\right)$ and obese $\left(\mathrm{BMl} \geq 30 \mathrm{~kg} / \mathrm{m}^{2}\right)$. US examination of Achilles tendon and plantar aponeurosis was performed by a blinded radiologist experienced in musculoskeletal US using a Philips HD11 device with a high-frequency linear transducer. Enthesitis was defined as hypoechoic and/or thickened insertion of the tendon close to the bone (within $2 \mathrm{~mm}$ from the bony cortex) which exhibits Doppler signal if active and that may show erosions, enthesophytes or calcifications as sign of structural damage. A p-value $<0.05$ was considered significant. Results: Sixty-two feet were examined in 31 RA patients (25 women and six men) with a mean age of $54.8 \pm 10.8$ years old [32-70]. The mean disease duration was $8.5 \pm 7.2$ years [1-37]. Rheumatoid Factor (RF) and Anti-Citrullinated Peptides Antibodies (ACPA) were positive in $61.3 \%$ and $83.8 \%$ of cases. The mean DAS28 ESR was 3.8 \pm 1.5 [0.6-7].

The mean BMI was $27.7 \pm 5.4 \mathrm{~kg} / \mathrm{m}^{2}$ [18.3-45.8]. Obesity was noted in $22.7 \%$ of patients and overweight in $45.5 \%$ of patients. Clinical examination revealed pes planus valgus (PPV) in $55.6 \%$ of cases and pes cavus varus (PCV) in $18.5 \%$ of cases. Heel US revealed Achilles enthesitis in $79.6 \%$ of cases. The following elementary lesions were noted in the enthesis: thickness (24.1\%), hypoechogenicity (37\%), erosions $(9.3 \%)$, enthésophytes $(75.9 \%)$, and Doppler signal $(3.7 \%)$. Plantar fasciitis was noted in $81.5 \%$ of cases. The following elementary lesions were found in the insertion of plantar aponeurosis: thickness (75.9\%), hypoechogenicity $(77.8 \%)$, erosions $(16.7 \%)$, enthesophytes $(13 \%)$, calcifications $(1.9 \%)$, and Doppler signal (1.9\%).

An association was noted between BMl and Achilles enthesitis $(p=0.002)$. This association was not found with plantar fasciitis $(p=0.224)$

Achilles enthesitis was also associated with PCV $(p=0.007)$ while plantar fasciitis was associated with PPV ( $\mathrm{p}=0.039)$.

Conclusion: Achilles enthesitis and plantar fasciitis are common in RA patients. These lesions seem to be associated with BMI and foot deformities rather than the inflammatory process.

Disclosure of Interests: None declared

DOI: 10.1136/annrheumdis-2021-eular.3194

\section{AB0172 ELDERLY ONSET RHEUMATOID ARTHRITIS (EORA): WHAT TO EXPECT IN REAL LIFE}

I. Coman ${ }^{1}$, I. Elisei², V. Bojinca ${ }^{1,2}$, D. Mazilu, ${ }^{1,2}$, S. Daia ${ }^{1,2}$, I. Saulescu, ${ }^{1,2}$ C. L. Constantinescu ${ }^{1,2}$, M. Abobului $^{1,2}$, A. Borangiu ${ }^{1,2}$, M. M. Negru ${ }^{1,2}$, C. Cobilinschi ${ }^{1}, 2$, M. Duna ${ }^{1}$, D. Predeteanu ${ }^{1}$, D. Opris-Belinski ${ }^{1}{ }^{1,2}$, L. Groseanu ${ }^{1,2}$, F. Berghea ${ }^{1,2}, A$. Balanescu ${ }^{1,2}, \mathrm{R}$. Ionescu ${ }^{1,2}{ }^{1}{ }^{1}$ Saint Mary Hospital, Rheumatology, Bucuresti, Romania; ${ }^{2}$ Carol Davila University of Medicine and Pharmacy, Medicine, București, Romania

Background: The term elderly onset of rheumatoid arthritis (EORA) refers to patients with rheumatoid arthritis (RA) onset after the age of 60. Data published in the literature suggest a special clinical pattern and different prognostic factors in this class of patients.

Objectives: To analyze prospectively a cohort of patients diagnosed with EORA, their disease particularities, comorbidities and treatment.

Methods: This cohort included consecutive EORA patients, diagnosed and treated in "Sfanta Maria" Clinical Hospital, Bucharest, Romania. The study was conducted for 2 years. Demographic, clinical and laboratory data was obtained. Disease activity was assessed using Disease Activity Score of 28 joints with erythrocyte sedimentation rate (DAS28-ESR). The patients were monitored using disease activity, treatment schedule modifications and possible adverse reactions.

Results: The cohort included 110 patients (88 females, 22 males). Their mean age at the beginning of disease manifestations was 70.14 years and the mean age at the diagnosis was 70.85 years. There was no statistica difference regarding the patient's residential area (urban/rural) and the period between the appearance of clinical signs and the moment of diagnosis confirmation. A great proportion of patients (77 patients, $70 \%$ ) had seropositive RA, ACPA being found in $84 \%$ of the patients with seropositive RA. The mean DAS28-ESR at the diagnosis was $4.44( \pm 1.54)$. A proportion of $40 \%$ of the patients had moderate disease activity, 35 patients $(32.73 \%)$ - high disease activity, 11 patients (10\%) - low disease activity and unexpectedly there were 19 patients $(17.27 \%)$ in remission at the moment of RA diagnosis. Joint distribution was analyzed: $61.82 \%$ patients had large joint involvement, $91.82 \%$ - small joint involvement and $53.64 \%$ had mixed joint pattern involvement. A negative significant correlation was found between the small joint involvement pattern and the body mass index $(B M I)(p=0.028, R=-0.21)$. The mean $\mathrm{BMI}$ at the diagnosis was $25.81 \pm 5.358$. Ninety five patients $(86,36 \%)$ had at least one cardiovascular comorbidity. Hypertension was found in $70 \%$ of the patients. Only $4.55 \%$ of the patients had rheumatoid nodules and a simila proportion (4.55) had Sjogren syndrome associated. Pulmonary fibrosis was found in only 2 patients. At the moment of diagnosis $50 \%$ of patients had anemia, $36.36 \%$ had osteoporosis, $25.46 \%$ of the patients - hepatic disease $11.82 \%$ - chronic kidney failure and $6.36 \%$ were found with a neoplasia. The main conventional synthetic disease modifying drug (csDMARD) that was recommended was methotrexate $(81.8 \%)$. The second most used csDMARD was hydroxichroloquine (42 patients, 38,18\%). The proportion of patients with monotherapy $(50 \%)$ was similar to that with csDMARD combination (49.09\%). During the follow up period only 8 patients $(7.27 \%)$ had biologic therapy (4 patients - an anti TNF drug). Non steroid anti-inflammatory drugs were used in $46.63 \%$. Cortisone therapy was used for more than 3 months in $80 \%$ of the patients. In patients with biologic therapy chronic glucocorticoids were stopped. At least one infection was documented in $20.91 \%$ of patients: 2 patients out of 6 patients (33.33\%) with biologic DMARD, $14.81 \%$ of the patients with csDMARD combination and $21.81 \%$ of the patients with csDMARD monotherapy. csDMARD therapy was well tolerated with only $23.63 \%$ adverse reactions.

Conclusion: Compared to the data published in the literature, in our cohort the rate female:male was higher (4:1). A distinct feature was the high proportion of patients with seropositive RA. The joint pattern seems to be influenced by BMI: small joint pattern is less found in patients with higher BMI. As expected, the patients with EORA had multiple cardiovascular comorbidities. Arterial hypertension was the most frequent. Caution is needed in choosing treatment regarding comorbidities and the risk of infection in these patients.

\section{REFERENCES:}

[1] Villa-Blanco JI, Calvo-Alén J. Elderly onset rheumatoid arthritis: differential diagnosis and choice of first-line and subsequent therapy. Drugs Aging. 2009;26(9):739-50

Disclosure of Interests: None declared

DOI: 10.1136/annrheumdis-2021-eular.3223 